\title{
An Analysis of Business Framework in identifying Customer Driven Demand Discovery
}

\author{
Are Karunakar Reddy ${ }^{1}$, Gunna Kishore ${ }^{2}$ \\ ${ }^{1}$ Computer Science and Engineering, Rise Krishna Sai Prakasam Group of Institutions, Ongole, India
}

\begin{abstract}
Customer Relationship Management (CRM) plays a vital role in identifying customer behaviour analysis which can help to a great extent of retaining the customers and providing an quality service to the customer.i Retail sector is an typical art of business, which requires an accurate identified approach in decisions making. CRM can be powered by data mining techniques in attaining to the right configuration or setting which help in finding right solutions On the other hand, the retailers are unable to predict the demand of products which may leads to inconsistencies in profit by the use of CRM. To overcome this disadvantage, an integrated version of CRM along with Supply Chain Management (SCM) is designed which affords the stock requirement from SCM based on the demand in CRM. Thus SCM with CRM enhances the retailers profit, meet the customer's demand and retain the current customers.
\end{abstract}

Keywords: Customer relation Management, Supply Chain Management, Retailer, Business, Data mining Techniques

\section{Introduction}

\subsection{Customer Relationship Management (CRM)}

Customer relationship management (CRM) is used to define the process of creating and maintaining relationships with business customers or consumers (Moon, 2003). A long-term relationship with the customer insures their repeat business. It costs more money to gain new customers than it does to retain current ones. CRM represents an endeavor approach to emerging full knowledge about customer behavior and preferences that promote customers to augment their business relationship with the company. It involves amalgamation of marketing, selling, customer services and supply chain functions of organization to achieve efficiency in delivering strategies.CRM mainly focus on collecting and understanding customer information, treating different customers differently. It affords higher level of service for the preeminent customers to increase customer loyalty and profitability. The use of Customer Relationship Management is becoming increasingly important to improve customer life time value. Due to the advancement of technology and constant changes, CRM sustain a long-term relationship with the customers.

Retailing is a bustle that involves buying goods or services and subsequently selling them to final customer usually in small quantities without transformation. Due to the increased competitiveness of retail activity, the relationship between companies and customers became a decisive factor of companies' strategy. With the proliferation of competitors, it became more difficult to magnetize new customers and consequently companies had to intensify efforts to keep current customers. In 2008 the retail sector employed a total of 17.4 million people in the EU $(8.4 \%$ of total EU workforce). The economic significance of this sector for the European Union is also revealed by its GDP share $(4.2 \%$ of EU's GDP in 2008).

\subsection{Supply Chain Management (SCM)}

Supply Chain Management recognizes all of conventional logistics and also includes activities such as marketing, new product materials development, and finance and customer service. It conveys a system approach to realize and dealing with the different activities needed to organize the flow of products and services to best supply the ultimate customer. Each group of customer has a specific set of requirements. The supply chains that provide different markets need to respond effectively to those requirements. To succeed in the competitive markets that make up today's economy; companies must learn to align their supply chains with the demands of the markets they serve.

\subsection{Integrating CRM and SCM}

Supply chain management (SCM) and customer relationship management (CRM) software are not usually mentioned in the same breath -- let alone SCM CRM integration -- and with good reason.

SCM software chugs along, ensuring that materials and information flow through the supply chain with the highest possible efficiency and the lowest possible cost. Meanwhile, CRM software focuses on the identification, targeting, acquisition and retention of customers, and on the building of strong relationships between the business and its customers.

Thus, the two tools tend to sit at opposite ends of the enterprise and deal with different sets of data albeit with the same end goal. There have been exceptions -- notably Dell Inc.'s famous skill at building to order, which was based in part on tight integration between customer-facing functions and supply chain elements.

For the time being, however, most organizations are not run like Dell so "connecting SCM and CRM is not an integration challenge in the traditional sense," said Simon Ellis, an 


\section{International Journal of Science and Research (IJSR) \\ ISSN (Online): 2319-7064 \\ Index Copernicus Value (2013): 6.14 | Impact Factor (2014): 5.611}

analyst with Manufacturing Insights. "CRM and SCM need to function in adjacent spaces and there needs to be a process that connects them loosely."

Still, even loose SCM CRM integration can be important. "We have all watched the economy over the last 18 months and it is clear that consumers are looking to get the bestpossible deals and they want to stretch their dollars further," Ellis said.

One implication of this trend has been the rapid increase in store brands or private label brands -- a trend that Ellis said can be offset by aligning sales and production, leveraging information to increase innovation and better management of the post-sales element of the customer relationship.[1]

A different approach of integrating both CRM and SCM is processed in which, a module is developed which intimates the demand from CRM to SCM. . In customer development module the products are categorized according to yearly, monthly, weekly, daily and seasonal based. So whenever demand occurs the stock availability is increased in SCM and provided to CRM which satisfy and retain the current customer.

\section{Related Work}

CRM can be defined as process of using information technology in implementing relationship marketing strategies, with particular emphasis on customer relationship. Nairn (2002) goes further and defines CRM as a long-term business philosophy that focuses on collecting and understanding customer information, treating different customers differently, providing a higher level of service for the best customers and using these together to increase customer loyalty and profitability [3].

Alhaiou et al proposed some benefits of CRM which includes lower cost of customers' acquisition, improvement of customer services, customer retention and loyalty increase, higher customers' profitability, easier identification of profitable customers and companies' productivity increase [4].Ngai et al categorizes analytical CRM on four dimensions [5]. Other related works in CRM are explained as follows,

Customer Identification includes mainly customer segmentation. It implies the subdivision of the set of all customers into smaller segments including customers with similar characteristics [6]. According to Kracklauer et al. (2004), customer satisfaction is the main issue regarding customers' retention. The customer's perception of the value offered by the company leads to sustained customer retention [8].

\section{Problem Definition}

Retailing is an activity that involves buying goods or services and selling them to final customers and maintaining the relationship with the organization. All the existing features regarding CRM is efficacy in delivering strategies but does not meet the customers demand. The main drawbacks in retail business are if products are sold in huge amount and high demand arises and subsequently if stock is not available it leads to inconsistencies of profit to the retailers. This paper produces an effective mechanism in designing integrated version of CRM along with SCM. Thus, to enhance retail business marketing, automatic generation of products are intimated from SCM to the development module of CRM. By the use of data mining techniques each module are scheduled. By considering various parameters, similar customers are identified and mainly occasional customers are converted to regular or valuable customers. In order to retain the current customers some attractive programs are developed.

\section{System Architecture}

Integration of CRM and SCM architecture clearly explains the process of grouping the frequent customers, how to amend occasional customers to regular customers by providing attractive programs. Finally, retaining of frequent customers and profitability is attained by this achievement.

\subsection{Grouping of similar customers}

Grouping of similar customers are evolved by exploiting various parameters such as product, customer and sales information from transaction database. Taking into account, that a retail company receives thousands of visits to its stores every day, it is not possible to know each customer personally. From managerial point of view, companies are not able to customize their relationship with each customer.

In order to establish and reinforce the relationship with customers, companies need to identify groups of customers who can be treated similarly. Fuzzy clustering techniques are applied in grouping of similar customers. The grouping process is mainly done by frequent visit of customers and amount spent by individual customers. According to threshold value the final output formed are valuable customers, regular customers and occasional customers where these output results are given as input to the business development module.

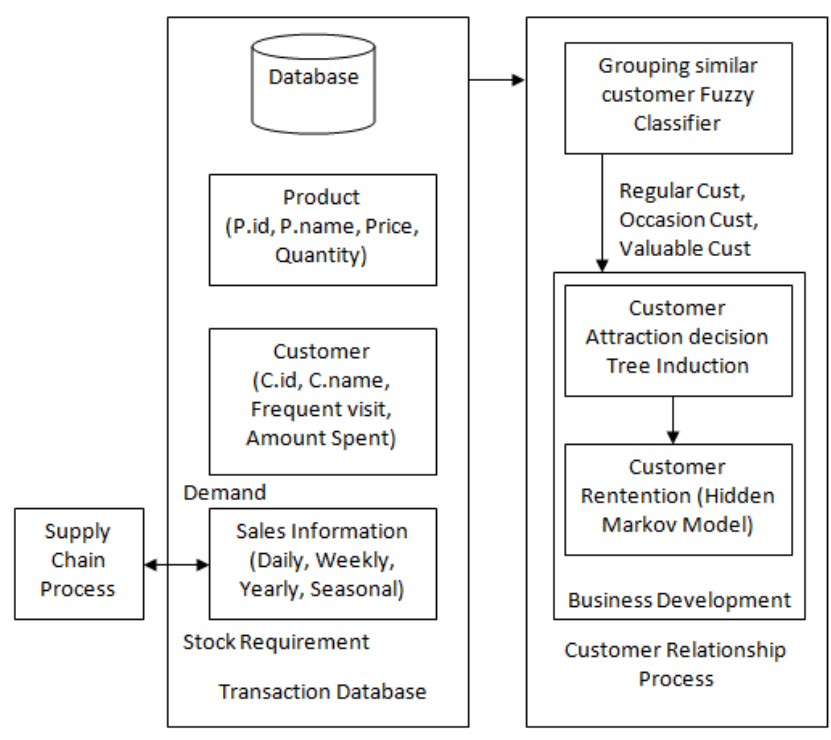

Figure 1: Predictive analysis of customer retention system 4.2. Business development

\section{Volume 4 Issue 12, December 2015}




\section{International Journal of Science and Research (IJSR) \\ ISSN (Online): 2319-7064}

Index Copernicus Value (2013): 6.14 | Impact Factor (2014): 5.611

In business development module, 2 criteria's are mainly concerned. First, the occasional customers are changed to regular or valuable customers by providing some attracting programs, discounts etc. second, by applying Data cube technology the yearly, monthly, weekly, daily and seasonal based sold products are verified and stored on the database. Considering these parameters if demand arises in CRM, then stock availability is automatically increased in SCM and is provided to CRM in order to meet the demand hence increasing the profitability and retaining of customers.

\subsection{Customer attraction and retaining the customers}

In customer attraction, discounts and some loyalty programs are conducted which motivates the customer to place an order immediately. Direct marketing and coupon distribution are some examples of customer attraction In customer retaining, predictive analysis of data mining techniques are applied, and analysis of whether the customer will retain or not are identified by hidden markov model with the help of product and customer details, some attractive programs are conducted specially to similar customers in order to retain the current customers. In this paper the main objective of organization is some intensify efforts are taken to retain the current customers and profit is also increased.

\section{Implementation}

CRM-SCM integration strives to satisfy and promptly deliver products to customers, ensuring availability of the product and maintaining profitability of the manufacturer.

In this paper, we have proposed the Algorithm by name "Apriori". By using this data mining algorithm we can know which product has the more demand. By knowing this the retailers can increase the number of those demanded products. We can know the type of the user like whether the user is a valuable, occasional, regular user. Based on that classification the retailers can attract the users.

This work is divided into four phases,
A. Product Registration.
B. Product Analysis.
C. Market position.
D. Product report.

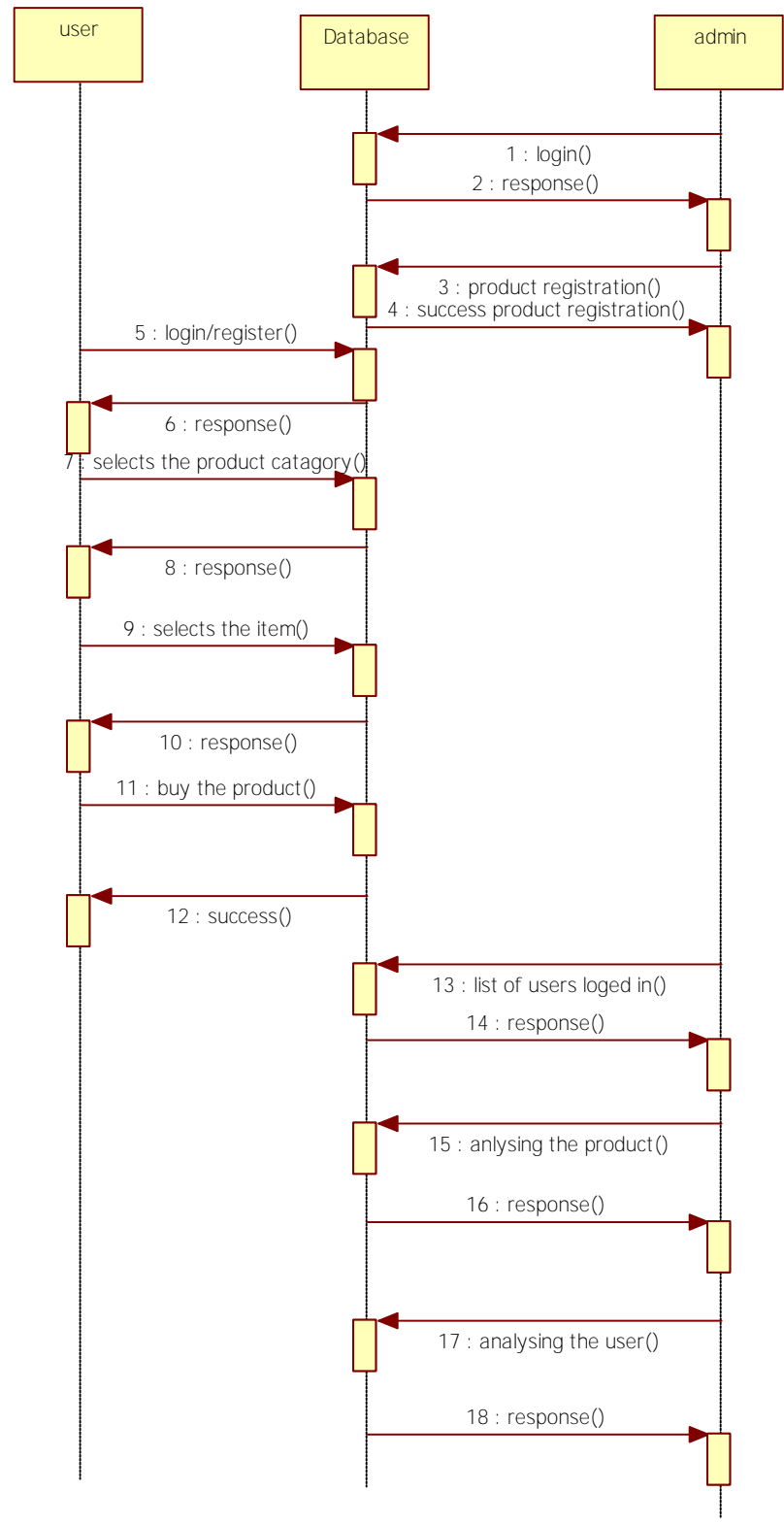

Figure 2: Data flow Diagram

\section{Apriori Algorithm}

- Algorithms for discovering large itemsets make multiple passes over the data. Apriori algorithm is the most established algorithm for frequent itemsets mining (FIM). Apriori is a seminal algorithm for finding frequent itemsets using candidate generation.

- Apriori-like algorithm is not of very high performance in comparison to others but it is more convenient to be realized for distributed processing in a grid computing environment due to its loosely coupled processes. 


\section{International Journal of Science and Research (IJSR) \\ ISSN (Online): 2319-7064}

Index Copernicus Value (2013): 6.14 | Impact Factor (2014): 5.611

Input: $N \_$vector $(E P, C)$, the set $C$ of customer requirements, the set $C P$ of candidate products, and the value of $k$

Output: a set of $k$ candidate products

1. For each candidate product $c p$ in $C P$

compute the satisfaction bit string of $c p$;

$C P S_{1}=\varnothing$

For each candidate product $c P$ in $C P$

$C P S_{1}=C P S_{1} \cup\{\{c p\}\} ;$

For $(l=1 ; l<k ; l++)$

$\{\mathrm{MAX}=0$;

For each $S$ in $C P S_{l}$

$\left\{\right.$ compute $U B_{-} E\left(k C P_{S}, C\right)$;

compute $L B_{-} E\left(k C P_{S}, C\right)$;

If $\left.\left(L B \_E\left(k C P_{S}, C\right)>M A X\right) M A X=L B \_E\left(k C P_{S}, C\right) ; \quad\right\}$

$C P S_{l}=$ CandidateCheck $\left(M A X, C P S_{l}\right)$;

$C P S_{l+1}=$ Apriori gen $\left(C P S_{l}\right) ;$

$M A X=0$;

For each $S$ in $C P S_{\text {, }}$

( compute $E(S, C)$;

If $(E(S, C)>M A X)$

$\{M A X=E(S, C)$

$k C P=S ;\}\}$

Return $k C P$

Function CandidateCheck $\left(M A X, C P S_{l}\right)$

For each $S$ in $C P S_{l}$

If $\left(M A X>U B \_E\left(k C P_{s}, C\right)\right)$

$C P S_{l}=C P S_{l}-\{S\}$

Return $C P S_{i}$;

Function Apriori_gen $\left(C P S_{l}\right)$

$C P S_{l+1}=C P S_{l} \otimes C P S_{l} ; \quad / /\left\{A \otimes B\left|A, B \in C P S_{l},\right| A \cap B \mid=l-1\right\}$

For each $S$ in $C P S_{l+1}$

If $\left((\right.$ any subset of $S$ with the size $\left.l) \notin C P S_{l}\right) C P S_{l+1}=C P S_{l+1}-\{S\}$;

Return $C P S_{l+1 ;}$

Apriori is an algorithm for frequent item set mining and association rule learning over transactional databases. It proceeds by identifying the frequent individual items in the database and extending them to larger and larger item sets as long as those item sets appear sufficiently often in the database. The frequent item sets determined by Apriori can be used to determine association rules which highlight general trends in the database: this has applications in domains such as medical analysis.

\section{Apriori Example}

Itemsets

$\{1,2,3,4\}$

$\{1,2,4\}$

$\{1,2\}$

$\{2,3,4\}$

$\{2,3\}$

$\{3,4\}$

$\{2,4\}$

We will use Apriori to determine the frequent item sets of this database. To do so, we will say that an item set is frequent if it appears in at least 3 transactions of the database: the value 3 is the support threshold.

The first step of Apriori is to count up the number of occurrences, called the support, of each member item separately, by scanning the database a first time. We obtain the following result.

Item Support

$\{1\} 3$

$\{2\} 6$

$\{3\} 4$

$\{4\} 5$

\section{Conclusion}

CRM-SCM integration strives to satisfy and promptly deliver products to customers, ensuring availability of the product and maintaining profitability of the manufacturer. From the analysis of the evolution of the retail sector, it is concluded that the reinforcement of relationship marketing is of utmost importance in today's context of thriving competition. The development of methodologies to support customer relationship management in retailing can increase companies' volume of sales. The effective integration of both CRM and SCM is designed by considering parameters of product, customer and sales information. Customer retention and profit is the expected outcome of assimilation of both CRM and SCM. The elucidation can be further enhanced by adding few more parameters to the transaction module of architecture could be dealt in future.

\section{References}

[1] http://searchmanufacturingerp.techtarget.com/tutorial/Int roduction-to-SCM-CRM-integration-Alan Earls [ONLINE]

[2] G. Yin, Yong. Data Mining: Concepts, Methods and Applications in Management and Engineering Design. Springer, 2011.

[3] Han, Shui Hua, Shui Xiu Lu, and Stephen CH Leung. "Segmentation of telecom customers based on customer value by decision tree model." Expert Systems with Applications 39.4 (2012): 3964-3973.

[4] Ngai, Eric WT, Li Xiu, and Dorothy CK Chau. "Application of data mining techniques in customer relationship management: A literature review and classification." Expert Systems with Applications 36.2 (2009): 2592-2602.

[5] Alhaiou, Talhat Almohamed. "A study on the relationship between E-CRM features and e-loyalty: The case in UK." (2011).

[6] Miguéis, Vera L., Ana S. Camanho, and Joao Falcao e Cunha. "Mining customer loyalty card programs: The improvement of service levels enabled by innovative segmentation and promotions design." Exploring Services Science. Springer Berlin Heidelberg, 2011. 8397.

[7] Woo, Ji Young, Sung Min Bae, and Sang Chan Park. "Visualization method for customer targeting using customer map." Expert Systems with Applications 28.4 (2005): 763-772.

[8] Prinzie, Anita, and Dirk Van den Poel. "Constrained optimization of data-mining problems to improve model performance: A directmarketing application." Expert Systems with Applications 29.3 (2005): 630-640.

[9] Kracklauer, A. H., Mills, D. Q., and Seifert, D. “ Customer management as the origin of collaborative customer relationship management" InCollaborative customer relationship management: taking CRM to the next level. Springer.154,2005.

[10] Van den Poel, Dirk, Jan De Schamphelaere, and Geert Wets. "Direct and indirect effects of retail promotions on sales and profits in the doit- yourself market." Expert Systems with Applications 27.1 (2004): 53-62. 


\section{International Journal of Science and Research (IJSR) \\ ISSN (Online): 2319-7064}

Index Copernicus Value (2013): 6.14 | Impact Factor (2014): 5.611

[11] Lo, Shu-Chuan. "Online customer identification based on Bayesian model of interpurchase times and recency." International Journal of Systems Science 39.8 (2008): 853-863.

[12] Sant'Anna, Annibal Parracho, and Rodrigo Otavio de Araujo Ribeiro. "Statistical modeling and probabilistic composition in the prediction of the customer lifetime value." Benchmarking: An International Journal 16.3 (2009): 335-350.

[13]Fader, Peter S., and Bruce GS Hardie. "Probability models for customer-base analysis." Journal of Interactive Marketing 23.1 (2009): 6. 